\title{
SignS AND TOOLS OF Algebraic REASONING: A STUDY OF MODELS AMONG Fifth GRADE STUdENTS
}

\author{
Kerri Richardson \\ The University of North Carolina at Greensboro
}

Made available courtesy of the Research Council on Mathematics Learning. No further reproduction is authorized without written permission by the Research Council on Mathematics Learning.

\section{Abstract}

This study focuses on the types of models created by students during algebraic pattern finding tasks. Attention is also given to the change in models over time. This is an important area of study because a closer look is needed to better understand the models created during mathematical activity, especially in the elementary classroom. It is reported here how fifth grade students used given concrete models and created new representations of models to reason algebraically about pattern finding tasks. Twenty-five fifth grade students participated in the three-day teaching experiment. Results indicate that students' recursive models were abandoned and then transformed to explicit models, and finally adopted from others during whole class discussions. These adopted models in most cases were enduring over a six-week period.

Standards-based classrooms served as a place for researchers and teachers to investigate different representational forms used and created by students (National Council of Teachers of Mathematics [NCTM], 2000). At the elementary grades in particular, coming to understand the processes involved in a child's representational thinking and how the tools created by such thinking help educators gain insight into students' mathematical generalizations (Smith, 2008). Lehrer and Schauble (2000) use the term "modeling" when speaking of the processes of representational thinking. Such processes include models used and/or created by teachers and students and the behaviors associated with them. Models can take the form of handdrawn pictures, symbols, and at the elementary grades in particular, informal written or verbal descriptions of mathematical ideas. In differentiating between various models, the case is made that early reasoning about models is centered on what students create for themselves (Lehrer \& Schauble, 
2000). Recent research has built on such modeling perspectives through the study of representations in relationship to probability and rational number concepts (Lee, Brown, \& Orrill, 2011; Zahner \& Corter, 2010). However, there is a gap in the literature about specific models and the analysis of such models that were created by elementary grades students during algebraic tasks.

Exploring students' generated models builds on the early algebra knowledge base (i.e., Kaput, Carraher, \& Blanton, 2008) in ways that allow educators to gain a better understanding between the relationships in student thinking about tasks and the creation of models as a result of such tasks. In the following sections, I note Vygotsky's perspective on signs and tools as relevant to modeling practices, the literature on modeling and representation, and a discussion of reasoning in concert with modeling.

\section{Signs and Tools}

Vygotsky (1978) discussed the idea of signs and tools as a unique aspect of human development. As noted by Forman (2003), Vygotsky emphasized the need to study the changes of signs and tools over time. Tools can be any number of things related to the hand - which in this particular study, pattern blocks were an important tool used by students. Signs, which include things like language, symbols, writing, and number systems, work in conjunction with tools. From a mathematics education perspective, studies in the changes of meaning of symbolic objects have been investigated (see Forman, 2003). Van Oers $(1996,2000)$ noted the development of a symbol such as five among children and how a child goes through a reification process in applying more and more meaning to the symbol. Lehrer, Schauble, Carpenter, and Penner (2000) found a connection between changes in symbols of mathematical ideas as related to classroom norms. Godino and Batanero (1996) offered validation to what students create themselves for the purpose of making sense during mathematical reasoning tasks. However, there is a lack of research in understanding the relationship between the change in signs and tools over time and the characteristics of the models themselves.

\section{Reasoning and Modeling}

Carraher and Schliemann (2007) define algebraic reasoning as, "A psychological process involved in solving problems that mathematicians can easily express using algebraic notation" (p. 670). However, a key part of algebraic reasoning in the elementary grades is justification of the generalization because it plays a key role in positioning student thinking as the central focus (Maher \& Davis, 1990). As is stated in my work with prospective elementary teachers, "With elementary students, justifications are more likely to take the form of a persuasive argument as to their thinking in relation to their generalization rather than a formal, mathematical proof "(Richardson, Berenson, \& Staley, 2009, p. 189). I mention reasoning in particular 
throughout this study because it is an integral part of modeling and involves generalizations and justifications made by students to support mathematical arguments (NCTM, 2000; Yackel \& Hanna, 2003). Research provides a range of frameworks in which to study the nature of reasoning and proof among students (i.e., Boesen, Lithner, \& Palm, 2010; Maher \& Martino, 1996; Stylianides \& Silver, 2004; Yackel \& Hanna, 2003). How students reason can have a powerful impact on the mathematical situations created by and presented to students. The focus here, then, is on the models created as a result of student reasoning which is an important pedagogical tool.

Modeling is best explained as an iterative process in which learners describe mathematical situations through a variety of model-eliciting activities (Lesh \& Doerr, 2003; Lesh \& Lehrer, 2003). Modeling and model-eliciting activities enable students to describe mathematical situations in meaningful ways that develop over time with the help of peers and teachers. In essence, modeling and model-eliciting activities are developmental and require refinement and reification. Therefore, forming more robust models - meaning models that support students' generalizations about early algebra tasks (Smith, 2008) - contribute to students' growth in understanding about tasks.

Lesh and Lehrer (2003) and Lesh and Doerr (2003) argue for modeling and model-eliciting activities as a shift in the way students and teachers engage in problems. The traditional view of problem solving involves a set of steps, which are many times stripped down to things like read, know, plan, solve, and check. Modeling perspectives can be part of problem solving but encompass more than just the steps or actions; modeling takes into account the constructs and processes that must be developed during mathematical activities. For example, modeling-eliciting activities include things like looking for patterns, sorting and classifying objects, organizing data, describing findings to peers, and traditional problem solving. Modeling then is an overarching design of what is possible in the mathematics classroom, and model-eliciting activities are those activities that are fundamental to the design.

The idea here is not to dive into each and every point of modeling design and model-eliciting activities, which can be found in Lesh and Doerr (2003). However, the focus on signs and tools with respect to modeling is an important area to expand upon. Built on Vygotsky's notion of conceptual tools, one particular aspect of modeling includes the idea of shared meaning. Vygotsky (1978) noted that certain signs have meaning to the individual but then cross over as tools of learning for others. Signs and tools then work hand in hand during the learning process and take on a variety of forms. The particular form in the work reported here involves pattern blocks, $\mathrm{T}$ or function tables, variables, and student-generated drawings. But the meaning behind all of these signs and tools is also important and discussed.

There are a variety of ways in which researchers can begin to understand connections between students' mathematical experiences and developmen- 
tal processes such as modeling practices. A classroom geared toward a modeling design contains a gamut of characteristics. Here I study one particular strand focusing on signs and tools. In the reported research, I look at modeling in a fifth grade classroom by focusing on the specific signs and tools used by students. By signs and tools, I mean things like drawings, use of pattern blocks, or any kind of visual model that is student generated for the purpose of reasoning about mathematical tasks. I build on a pilot study in which I focused on one student's signs and tools (Richardson \& McGalliard, 2010) to now look at the signs and tools of the larger group of fifth grade students. Therefore, my focus is on how large and small groups utilize signs and tools during a classroom teaching experiment over a three-day time span and during individual interviews that occurred six weeks later.

Using a conceptual framework (Eisenhart, 1991), I describe both the characteristics of and relationships between various models that were created by fifth-grade students during algebraic pattern finding tasks. In particular, I address the following questions:

1. What models are created and utilized by fifth grade students during pattern finding explorations that require algebraic reasoning?

2. How enduring are student models throughout pattern finding explorations?

\section{Conceptual Framework}

The conceptual framework developed for this study draws from Lesh and Doerr's (2003), Lesh and Lehrer's (2003) modeling perspectives, and from Vygotsky's (1978) perspectives on signs and tools. Lesh and Doerr (2003) and Lesh and Lehrer (2003) note the iterative nature of modeling and model-eliciting activities. Their systemic view of models is that they are parts of systems used to express the behaviors of other systems. In the case of mathematics, the larger system is a concept and the part of the system is a model of that concept. In this study, my interests are on external notational systems such as the pattern blocks formed, pattern block models drawn on paper by students, and any transformation of drawn pattern block models. I will also focus on other systems that assist me in understanding the pattern block models such as T tables, written descriptions of pattern block models, and verbal descriptions of models. In short, I draw on the modeling framework from two perspectives: (a) the iterative nature of the models and how they evolve for the individual over time, and (b) the external notational systems students used. I will refer to all of the aforementioned notational systems as models but be mindful in specifying differences as needed. It is important to note that components of the modeling framework do stem from Vygotsky's perspective on signs and tools, but I give further attention to the idea. Vygotsky (1978) noted that when a child is faced with what they perceive to be a difficult task, she or he often times looks to a tool of some 
kind in order to begin sense making. That tool may pass through several children in the same situation, thus enabling each child to make sense of a particular task in a way that is most meaningful to them. Therefore, I also study closely the sharing of models.

\section{Research Methodology}

\section{Context and Sources of Data}

The number of students who participated in this study was 25 , all of whom were average to above average in mathematical achievement as measured by the work graded and reported by the classroom teacher. Averaging 11 years old, these fifth grade students attended a rural elementary school in the southeastern part of the United States. Most were Caucasian. The school itself has a science/mathematics focus, and the teacher of the class regularly engaged the students in a variety of rich algebraic tasks. Previously, the teacher of the class engaged the students in examples that practiced the use of algebraic notation to solve equations. However, it did not appear that the students had experience in finding patterns and generalizing rules. There were six total researchers who assisted during the teaching experiment with one lead researcher teaching the lessons. I was one who assisted in the study. The teaching experiment design (Lesh \& Kelly, 2000) was chosen because it was the most appropriate way to find out how students were thinking about the algebraic concepts that were presented. Task-based interviews (Goldin, 2000) were also used to assist in finding more details about how the students reasoned through each task.

The teaching experiment lasted for three consecutive days, one and a half to two hours each time. Students worked in pairs throughout each day and discussed ideas as a whole group and with their partner depending on the phase of instruction. Audio and video data were used to collect the work of 12 students dyads, and follow up interviews of 14 students were conducted six weeks later. The 25 th student worked along because we did not have a consent form for the first day. The 14 students were chosen based off their written work and conversations with peers and researchers during the teaching experiment. Some were chosen because they simply volunteered, while others were chosen because we wanted to ask more specific questions about the models they drew to understand their reasoning.

Sources of data included video footage of student explorations, audio recordings of conversations, transcripts, and written work. Videos were transcribed, and pseudonyms were used in all cases. As stated earlier, in the preliminary study (Richardson \& McGalliard, 2010) we focused on only one student. In this study, I look at an entire class of 25 fifth grade students. 


\section{Task and Instruction}

The role of the researcher during this three-day teaching experiment was to facilitate instruction with both the small and large groups of students. Two other researchers (myself included) took field notes and provided clarification as needed while three doctoral students video-recorded large and small group student interactions. Day one of the teaching experiment involved a context in which students could imagine - people sitting around tables. The task consisted of asking students how many people could sit around one square table if only one person was allowed on each side. Next, two square tables configured side-by-side, then three, and so on (see Figure 1).

Day 1 - If you have one square table, how many chairs will fit around the table if you have one chair on each side of the square? Two square tables? Three square tables? Do you see a pattern yet? If yes, write down a description of your number pattern.
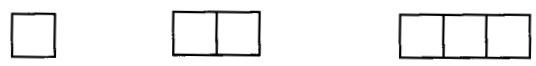

Figure 1. First task investigated by fifth grade students in an algebraic reasoning teaching experiment.

Each child received blank paper, square pattern blocks, and markers to investigate the task. The lead researcher asked students to record their explorations on the paper provided and encouraged them to record their data in an input/output table, demonstrating how to do this on a document camera. Students were able to give a variety of labels to the two variables including the number of people, chairs, and tables. Some cameras were positioned at random groups while other cameras at the entire class. Students asked for extra paper because many of them insisted on tracing the actual pattern blocks to demonstrate the first four or five builds.

After exploring for about 15 minutes, students were asked if they recognized any patterns in the $\mathrm{T}$ tables they had filled in and/or the pattern blocks they built and subsequently drew. They were then prompted to think about how people could sit around ten tables, then 20 , and finally 100 . The goal of the first day was for students to recognize a pattern and possibly even an informal or formal rule.

Day two involved the same task but with triangles and the third day with hexagons (see Figures 2 and 3). We also gave a final worksheet involving a series of pattern blocks.

\section{Data Analysis}

My overarching analysis draws from Lesh \& Lehrer's (2003) conceptions of what they call a "modeling cycle." During a modeling cycle, a host of 
Day 2 - If you have one triangular table, how many chairs will fit around the table if you have one chair on each side of the triangle? Two triangular tables? Three triangular tables? Do you see a pattern yet? If yes, write down a description of your number pattern.

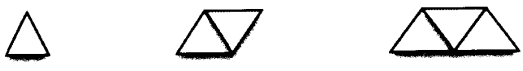

Figure 2. Second task investigated by fifth grade students in an algebraic reasoning teaching experiment.

Day 3 - If you have one hexagon table, how many chairs will fit around the table if you have one chair on each side of the hexagon? Two hexagonal tables? Three hexagonal tables? Do you see a pattern yet? If yes, write down a description of your number pattern.

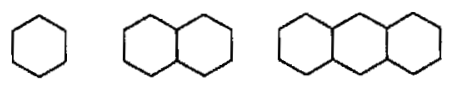

Figure 3. Third task investigated by fifth grade students in an algebraic reasoning teaching experiment.

aspects are considered. Here I pay close attention to signs and tools (e.g., pattern block trains, $T$ tables, etc.), the nature of these signs and tools for the purpose of understanding how models are both created and adopted by students, and how the models change over time.

In my analysis, I watched all three days of video data while matching up transcripts and student work samples to give me a more clear understanding of each occurrence during the teaching experiment. I went through student work samples from the first day and looked for the initial models created by students in relations to the pattern blocks. If a student work sample needed more explanation, I would refer to the transcript and/or video data for clarification. Then I looked at nature of other models that were created for the purpose of helping a student explain their initial pattern block model such as $T$ charts and written explanations. Since the students were asked to model the question posed to them, all written work reflected a pattern block model, a $\mathrm{T}$ chart, and some sort of written explanation. The study was bound to a three-day teaching experiment plus follow-up interviews six weeks later. Therefore, the approach I used as an embedded analysis of themes in which I used an open-coding approach (Creswell, 2007).

First, I coded the data for the models students developed and how those models changed over the course of the teaching experiment and followup interviews. Then, I recorded the data for the signs and tools students employed in these models. This included models developed by individual students, small groups of students, and the large group. What I mean by this is during different phases of instruction, the lead researcher would ask the entire class questions and then the pairs would address the questions together, but also present their ideas to the entire group at certain times during the 
teaching experiment. As a result, students sometimes changed a drawing or re-wrote a rule because what they saw projected on the classroom document camera made more sense to them, etc. We knew this was happening because some would ask for additional sheets of paper to make a new drawing or write out a new rule. Finally, I identified common themes among the data that described the development of models over time for students.

\section{Results}

\section{Abandoned Models}

The first and most basic type of model that occurred for the students was a depiction of the pattern's blocks themselves. I call these abandoned models because they serve as an entry point for students thinking about a mathematical task. However, abandoned models played an important role for the students in making sense of the task initially, but in this study, were never drawn again (all days and follow-up interviews included). Zahner and Corter (2010) would term such models as pictorial representations because the students literally drew or traced the pattern blocks. Vygotsky (1978) poised that when a student is unsure what to do, they utilize something as a starting point. The tracing of the pattern blocks was an entry into the problem but was soon abandoned for a more efficient approach. One student used an artistic interpretation (see Figure 4). About half of the students drew the tables by tracing the actual square pattern blocks on paper and then labeling the action of each square in relation to the number of people seated using only numbers and words (see Figure 5).

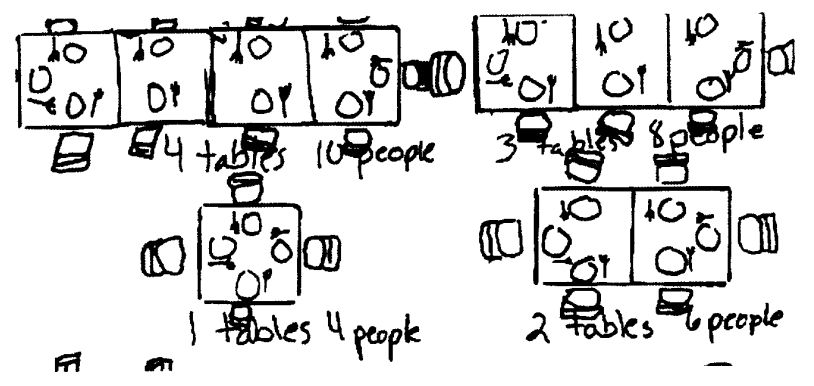

Figure 4. A student's model of the square tables task.

The same was true for triangles and hexagons. The way students labeled their models differed slightly - some writing their words below the blocks, others inside, and some all the way around the model (see Figure 6).

The pattern blocks were a starting point for students to become involved with the problem and all drew some sort of a variation that closely resem- 

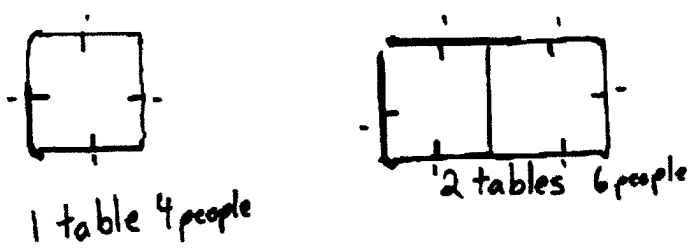

Figure 5. The tracing and labeling of pattern blocks.

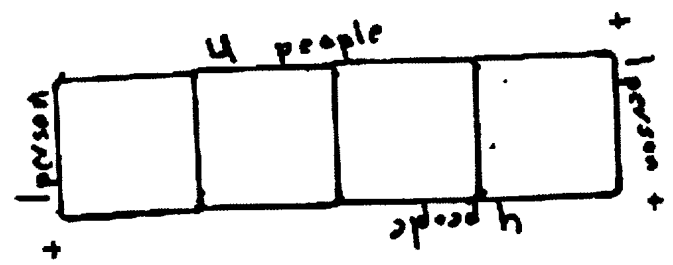

Figure 6. The tracing and labeling of pattern blocks on each side.

bled the models shown in Figures 4, 5, or 6. However, these were all abandoned as the questions about how many tables and people who could sit around the tables increased. For example, when the lead researcher asked, "How many people could sit around a group of 10 tables (aligned continuously side-by-side) if only one person were allowed on each exposed side?" Suddenly, some of the students referred to their function tables and noticed a pattern. They simply continued filling in the number of tables on the first column and the number of people on the second column until they reached 10 . They could see the pattern produced an answer of 22 . Not one student drew or traced 10 squares side by side. Many were asked to describe the rule they saw.

Twelve students used the language of "people" and "tables" to describe the patterns found on all three days. For example, the most common rule written down for the square tables task was, "add a table, add two people" and "add two people each time you add a table." The remaining students made an immediate jump to a numerical description of the patterns found (e.g., "multiply T by 2 and add 2 equals P"). It was the next question of 100 tables as opposed to 10 that generated a transformation of models.

\section{Transformed Models}

A new set of drawings were created by students that I call transformed models because the students used the initial patterns block drawings to visualize people sitting around tables but then changed that model into something more abstract. Zahner and Corter (2010) would term these schematic representations because students started creating something to help them make sense of the problem. However, my description is in relationship to the initial abandoned models. Therefore, a transformed model is a model 
that possesses characteristics unique to the learner. Figures $7,8,9$, and 10 are examples of transformed models and these came about when students were asked, "How many people could sit around a group of 100 tables (aligned continuously side-by-side) if only one person were allowed on each exposed side?"

This question was a major turning point during the teaching experiment because students (all still working in pairs, but interacting between one another and the entire class) suddenly realized it would take a very long time to either draw 100 squares side-by-side or fill in their function tables all the way to 100 . The 100-table question required that the students abandon their recursive thinking and search for another strategy. So, they knew they must come up with a more efficient way to investigate the problem. About half of the class verbally said to their partner or noted in their written work that you must multiply 10 by 22 . As noted in one transcript:

Jenny: Ten tables equals 22 people and so I did ten times 22 and got 220 . During this time several students shouted out 202 as the answer. One student in particular, Dan, led the transformation as noted in the following script:

Lead Researcher: Wow, I never thought of doing it that way. That's how you could get 220. But how can you get 202? Yes, you haven't gotten up yet. Your name is Dan.

LR: Big loud voice now. So which answer do you think is right?

Dan: 202.

Dan: It would be like 100 tables on this side, add that together would be 200 and then one, two, so that's 202 [all of this as he is pointing to his drawing in Figure 7].

After Dan explained his model, other students started drawing their own models, as seen in Figures 8-12.

The lead researcher asked Dan to further clarify after a student expressed her confusion:

LR: And why does it work that way, Dan?

Dan: Because if you had 100 tables, it would be a 100 on either side. Then the ends would count as one, so 202.
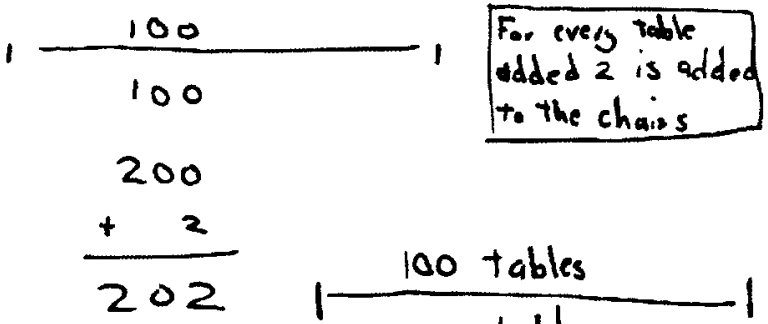

Figure 7. Square pattern block transformation to a line. 


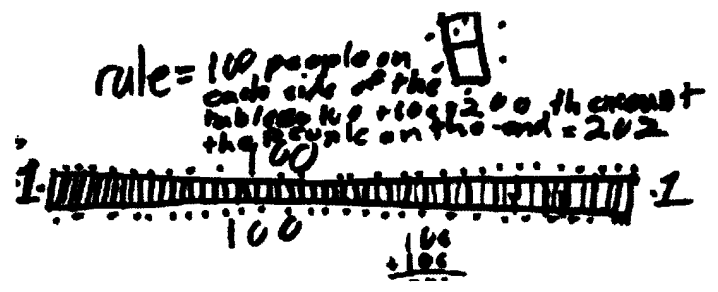

Figure 8. Square pattern block transformation to a series of marks.

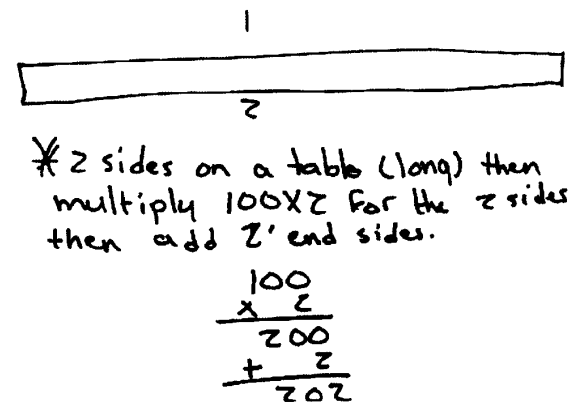

Figure 9. Square pattern block transformation to a rectangle.

Several more students came to the document camera with their models and shared similar solutions while pointing to their transformed models. After several shared, the students who previously thought the answer was 220 were convinced the answer was 202 as indicated in the transcripts and their written work. A third category of models I found were that of adopted models.

\section{Adopted Models}

When a student was able to use their transformed model to justify the 100-table question, I then categorized that model as being adopted by the

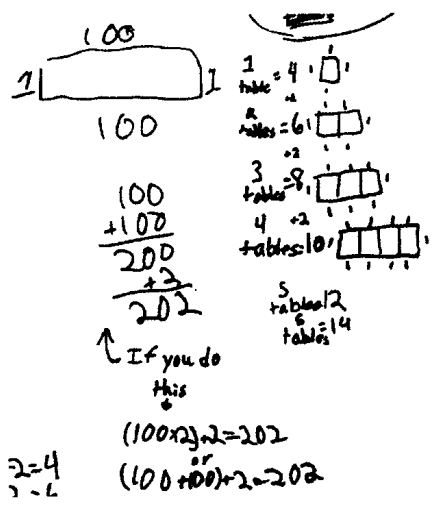

Figure 10. Nora's large rectangular transformation $\&$ adoption of the model. 
student. An adopted model is a model that a student uses to make a generalization or justification. It was not until Dan demonstrated his line model that other students started transforming their own models and then adopting some form of Dan's model. Through verbally asking students or analyzing their written work, I was able to find out who used their transformed model to an adopted one for the purpose of justifying the answer of 202. As seen in Figure 11, Anna transformed her own model and then adopted Dan's model directly to write her solution to the 100-table question. Nora (see Figure 10) did the same as well as 15 other students.

It was difficult to discover conclusively who adopted the model to find the solution of 202 because students simply wrote down what Dan said in sentence form after his verbal description. However, due to the large research team spread throughout the classroom, we were able to observe fairly well those who drew their own version of Dan's model and wrote justifications in their own words. For additional clarification, we interviewed 14 students six weeks later for the purpose of finding out what they remembered about the pattern problem along with new insights they had. As a result, I found models that endured over time.

Figure 11. A vertical transformation.
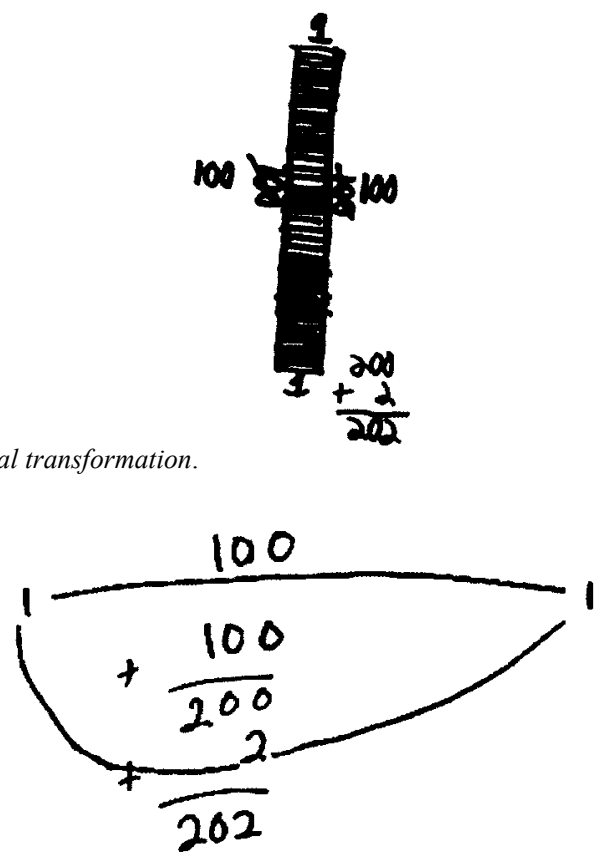

Figure 12. Anna's adoption of Dan's model.

\section{Enduring Models}

An enduring model is one that stays with a student over time and is put 
to use by the student when posed with a new task to investigate. Enduring models possess the characteristics of having already been transformed and adopted. During the follow-up interviews that occurred six weeks later, we asked students to solve the pattern table task but with two people sitting on each side of the table instead of one. Out of the 14 students interviewed, nine drew a form of the model that was transformed and/or adopted from day one, hence an enduring model (e.g., see Figure 13). The remaining students modeled the idea through words and/or symbols (e.g., see Figure 14). During days two and three, students used words and symbols to describe the pattern task with triangles, hexagons, and pentagons (e.g., see Figures 15 \& 16). The use of models in this way endured during the interviews, as well.

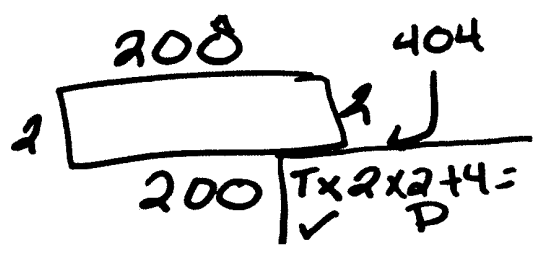

Figure 13. Enduring model from student interviews.

$$
\begin{aligned}
& 1 \times 4+4=8 \\
& 2 \times 4+4=12 \\
& T \times 4+4=C \\
& 100 \times 4+4=44404
\end{aligned}
$$

Figure 14. Enduring model of symbols from student interviews.

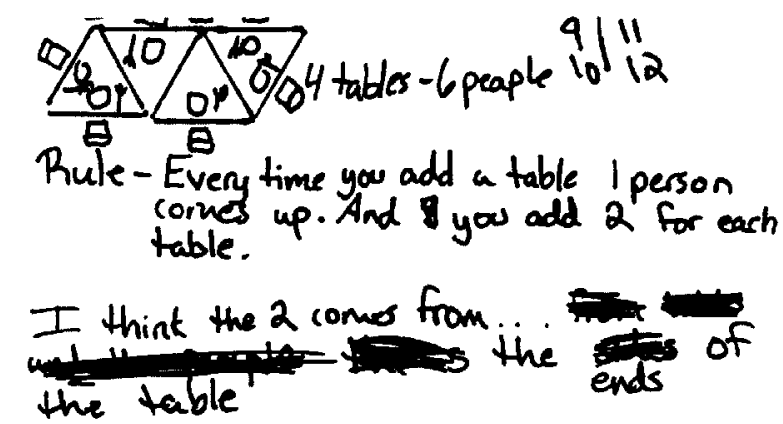

Figure 15. Triangle example. 
Not only did a form of Dan's line model endure into the interviews, a host of symbolic and word models surfaced, as well.

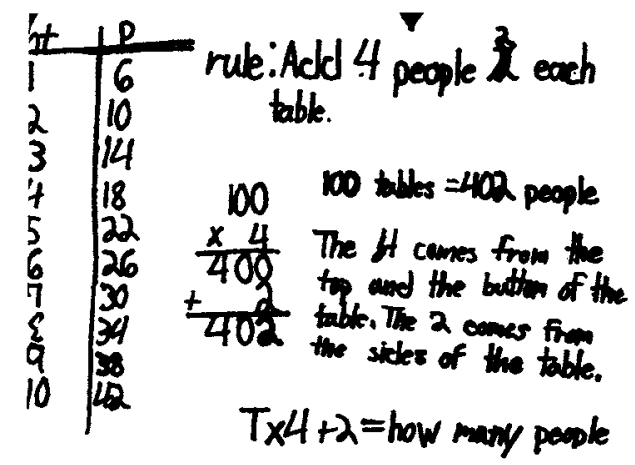

Figure 16. Hexagon example.

\section{Discussion}

This study focused on how large and small groups utilize signs and tools while engaged in algebraic pattern finding tasks. The results indicate that while students engaged in similar forms of modeling during initial stages of task exploration they abandoned these models to transform and sometimes adopt them, moving from recursive reasoning to explicit generalizations. In most cases they were able to justify these generalizations using their models. In an earlier study with preservice teachers, a majority of the participants focused on the end piece of the pattern block tables rather than the model as a whole (Richardson, et al., 2009). In this study, most students were able to focus on the entire model, adopting one student's model presented during the whole class discussion. On the whole, students did not revert to recursive strategies even though the tasks changed.

In addressing the research questions, I examined the kinds of models produced by fifth grade students initially and how those models changed over time. A variety of transformed models in the form of drawn pattern blocks, function tables, symbolic notation, and written explanations of patterns were found. Examining similarities and differences in the models produced and whether those models had an impact on the class as a whole, I found one student model, presented to the large group, which was adopted by most of the members of the class. The majority of interviewees remembered the adopted models they had previously drawn and used them once again to justify and reason through their solutions.

As a result of exploring my research question, I developed a system that examines models over time. Consisting of abandoned, transformed, adopted, and enduring models, these four categories are not always separate and can indicate overlapping depending on the sort of task being offered. A stu- 
dent may take an abandoned model and transform it to help them describe a mathematical idea. This process may lead to an adopted model if the student then uses the model to make a mathematical generalization. If that student transfers such a model to a new task, the model has endured over time. For a connected task (Richardson, Carter, \& Berenson, 2010) such as the ones posed in this teaching experiment, the development of models over time align with student understandings of patterns found as indicated by a close examination of the data. There remain a number of unanswered questions about what catalyzes abandoned, transformed, adopted, and enduring models. More study is needed to fully understand these progressions.

\section{ACKNOWLEDGEMENTS:}

I would like to personally thank Dr. Sarah Berenson for her help in both editing this paper and leading this teaching experiment.

\section{References}

Boesen, J., Lithner, J., \& Palm, T. (2010).The relation between types of assessment tasks and the mathematical reasoning students use. Educational Studies in Mathematics, 75(1), 89-105.

Carraher, D. W., \& Schliemann, A. D. (2007). Early algebra and algebraic reasoning. In F. K. Lester (Ed.), Second handbook of research on mathematics teaching and learning (Vol. 2, pp. 669-705). Charlotte, NC: National Council of Teachers of Mathematics (Information Age Printing).

Creswell, J. (2007). Qualitative inquiry and research design: Choosing among five approaches (2nd ed). Thousand Oaks, CA: Sage Publications, Inc.

Eisenhart, M. A. (1991). Conceptual frameworks for research circa 1991: Ideas from a cultural anthropologist; Implications for mathematics education researchers. In R. G. Underhill (Ed.), Proceedings of the thirteenth annual meeting of the North American Chapter of the International Group for the Psychology of Mathematics Education (Vol. I, pp. 229-239). Blacksburg, VA: Christiansburg Printing

Foreman, E. A. (2003). A sociocultural approach to mathematics reform: Speaking, inscribing, and doing mathematics within communities of practice. In J. Kilpatrick, G. Martin, \& D. Schifter (Eds.) A research companion to the NCTM Standards (pp. 333-352). Reston, VA: National Council of Teachers of Mathematics.

Godino, J. D. \& Batanero, C. (1998). Clarifying the meaning of mathematical objects as a priority area of research in mathematics education. In A. Sierpinska (Ed.), What is Research in Mathematics Education, and 
What Are its Results? (pp. 177-195) Dordrecht: Kluwer A. P.

Goldin, G. A. (2000). A scientific perspective on structured, task-based interviews in mathematics education research. In A. K. Kelly \& R. A. Lesh (Eds.), Handbook of research design in mathematics and science education (pp. 517-545). Mahwah, NJ: Lawrence Erlbaum.

Kaput, J. J., Carraher, D., \& Blanton, M. (Eds). (2008). Algebra in the early grades. Mahwah, NJ: Lawrence Erlbaum.

Lee, S. J., Brown, R. E., \& Orrill, C. H. (2011). Mathematics teachers' reasoning about fractions and decimals using drawn representations. Mathematical Thinking and Learning, 13(13), 198-220.

Lehrer, R., \& Schauble, L. (2000). Modeling in mathematics and science. In R. Glaser (Ed.), Advances in instructional psychology: Educational design and cognitive science (pp. 101-159). Mahwah, NJ: Erlbaum.

Lehrer, R., Schauble, L., Carpenter, S., \& Penner, D. E. (2000). The interrelated development of inscriptions and conceptual understanding. In P. Cobb, E. Yackel, \& K. McClain (Eds.), Symbolizing and communicating in mathematics classrooms: Perspectives on discourse, tools, and instructional design (pp. 325-360). Mahwah, NJ: Lawrence Erlbaum Associates.

Lesh, R. A. and Kelly, A. E.: (2000). 'Multitiered teaching experiments'. In A. E. Kelly and R. A. Lesh (Eds.), Handbook of Research Design in Mathematics and Science Education, (pp. 197-230). Mahwah, NJ: Lawrence Erlbaum.

Lesh, R., \& Doerr, H. M. (2003). Foundations of a models and modeling perspective on mathematics teaching, learning, and problem solving. In R. Lesh \& H. M. Duerr (Eds.) Beyond constructivism: Models and modeling perspectives on mathematical problem solving, learning and teaching (pp. 3-33). Mahwah, NJ: Lawrence Erlbaum Associates.

Lesh, R., \& Lehrer, R. (2003). Models and modeling perspectives on the development of students and teachers. Mathematical Thinking and Learning, 5(2/3), 109-129.

Maher, C., \& Davis, R. (1990). Building representations of children's meanings. In R. Davis, C. Maher, \& N. Noddings (Eds), Constructivist views on the teaching and learning of mathematics. Journal for Research in Mathematics Education Monograph (pp. 79-90). Reston, VA; NCTM

Maher, C. A. \& Martino, A. M. (1996). The development of the idea of mathematical proof: A 5-year case study. Journal for Research in Mathematics Education, 27(2), 194-214.

National Council of Teachers of Mathematics (NCTM). (2000). Principles and standards for school mathematics. Reston, VA: NCTM.

Richardson, K., Berenson, S., \& Staley, K. (2009). Prospective elementary teachers use of representation to reason algebraically. Journal of Mathemtics Behavior, 28(2/3), 188-199. 
Richardson, K., Carter, T, \& Berenson, S. (2010). Connected Tasks: The Building Blocks of Reasoning and Proof. Australian Primary Mathematics Classroom, 15(4), 17-23.

Richardson, K., \& McGalliard, W. (2010). Traveling representations in a fifth grade classroom: An exploration of algebraic reasoning. In $\mathrm{C}$. Pinchback (Ed.), Proceedings of the 37th annual meeting of the Research Council on Mathematics Learning (pp. 37-43) Conway AR: University of Central Arkansas.

Smith, E. (2008). Representational thinking as a framework for introducing functions in the elementary curriculum. In J. J. Kaput, D. W. Carraher $\&$ M. L. Blanton (Eds.), Algebra in the early grades up (pp. 133-160). New York: Lawrence Erlbaums.

Stylianides, G. J., \& Silver, E. A. (2004). Reasoning and proving in school mathematics curricula: An analytic framework for investigating the opportunities offered to students. In D. E. McDougall \& J. A. Ross (Eds.), Proceedings of the 26th Annual Meeting of the North American Chapter of the North American Chapter of the International Group for the Psychology of Mathematics Education (Vol. 2, pp. 611-619). Toronto, Canada: OISE/UT

van Oers, B. (1996). Learning mathematics as a meaningful activity. In L. Steffe, P. Nesher, P. Cobb, G. Goldin, \& B. Greer (Eds.), Theories of mathematical learning (pp. 91-115). Hillsdale, NJ: Lawrence Erlbaum Associates, 1996.

van Oers, B. (2000). The appropriation of mathematical symbols. A psychosemiotic approach to mathematics learning. In P. Cobb, E. Yackel, $\&$ K. McClain (Eds.), Symbolizing and communicating in mathematics classrooms. Perspectives on, tools, and instructional design (pp. 133176). Mahwah: Erlbaum.

Vygotsky, L. S. (1978). Mind in society. Cambridge, MA: Harvard University Press

Yackel, E., \& Hanna, G. (2003). Reasoning and proof. In J. Kilpatrick, W. G. Martin, \& D. Schifter (Eds.), A research companion to Principles and Standards for School Mathematics (pp. 227-236). Reston, VA: NCTM.

Zahner, D., \& Corter, J. E. (2010). The process of probability problem solving: Use of external visual representations, Mathematical Thinking and Learning, 12(2), 177-204. 